\title{
ИЗУЧЕНИЕ ВЛИЯНИЯ ПРИРОДЫ ЗАМЕСТИТЕЛЯ НА АКТИВНОСТЬ И СЕЛЕКТИВНОСТЬ НЕКОТОРЫХ ПРОИЗВОДНЫХ АЛКАЛОИДА ФАСКАПЛИЗИН
}

\author{
М.А.Сидорова, С.А. Дышловой, М.Е. Жидков
}

Школа Естественных Наук, Дальневосточный Федеральный Университет (ДВФУ), 690922 , Россия, г. Владивосток, о. Русский, п. Аякс, 10.

DOI: 10.19163/MedChemRussia2021-2021-309_E-mail: sidorova_ma@students.dvfu.ru

Сегодня вторичные метаболиты, подобные алкалоиду морского происхождения фаскаплизин (1), рассматриваются в качестве перспективных соединений-лидеров для разработки новых лекарственных препаратов, поскольку обладают широким спектром биологической активности [1-3]. Однако токсичность фаскаплизина не позволяет его применение в медицине. Поэтому нами была разработана схема синтеза ряда его производных по положению 9: 9-бромфаскаплизин (2), 9-йодфаскаплизин (3), 9-фенилфаскаплизин (4).<smiles>[R]c1ccc2[nH]c3c4c(=O)c5ccccc5[n+]4ccc3[R]([H])([H])c2c1</smiles>

Впоследствии для полученных соединений были изучены цитотоксическая активности и селективности на культурах опухолевых и неопухолевых клеток (таблица).

Таблица

\begin{tabular}{|c|c|c|c|c|c|}
\hline & \multirow{2}{*}{ Культура } & \multicolumn{4}{|c|}{ IC50, мкмоль/л } \\
\hline & & 1 & 2 & 3 & 4 \\
\hline \multirow{5}{*}{$\begin{array}{l}\text { Опухолевые } \\
\text { клетки }\end{array}$} & PC-3 & 0,77 & 2,78 & 3,67 & 1,95 \\
\hline & 22Rv1 & 0,24 & 1,07 & 0,55 & 0,31 \\
\hline & DU145 & 0,80 & 2,24 & 0,32 & 0,66 \\
\hline & LNCaP & 0,41 & 1,41 & 0,17 & 0,57 \\
\hline & VCaP & 0,58 & 2,56 & 2,22 & 1,27 \\
\hline \multirow{4}{*}{$\begin{array}{l}\text { Неопухоле- } \\
\text { вые клетки }\end{array}$} & MRC-9 & 0,89 & 15,54 & 0,92 & 4,25 \\
\hline & PNT2 & 0,46 & 2,45 & 0,15 & 0,76 \\
\hline & RWPE-1 & 0,50 & 1,54 & 0,14 & 1,50 \\
\hline & HEK293 & 0,46 & 2,54 & 0,81 & 1,94 \\
\hline \multicolumn{2}{|c|}{ Индекс селективности } & 1,03 & 2,74 & 0,36 & 1,47 \\
\hline
\end{tabular}

Выявлено, что для 9-йодфаскаплизин (3) лучшие показатели цитотоксической активности, при этом 9-бромфаскаплизин (2) имеет лучшие показатели селективности.

\section{Литература}

[1] R. Soni, L. Muller, P. Furet, J. Schoepfer, C. Stephan, S. Zunstein-Mecker, H. Fretz, B. Chaudhuri // Biochem. Biophys. Res. Commun-2000.- № 275.- P. 877-884.

[2] S. Manda, S. Sharma, A. Wani, P. Joshi, V. Kumar, S. K. Guru, S. S. Bharate, S. Bhushan, R. A. Vishwakarma, A. Kumar, S. B. Bharate// European Journal of Medicinal Chemistry.2016.-№107.- P. 1-11.

[3] T. A. Johnson, L. Milan-Lobo, T. C Lorig-Roach, P. Crews, J. L. Whistler // ACS Chemical Neuroscience. - 2016.- V. 8, № 3.- P. 473-485.

$$
-309-
$$

